\title{
Effect of the dewatering on the surrounding terrains during the construction of Metrostation 9-III of the Sofia Metropoliten
}

\section{Влияние на водопонижението при изграждането на Метростанция 9-III от Софийския Метрополитен върху околното пространство}

\author{
Ina Bojinova-Popova \\ Ина Божинова-Попова \\ University of Mining and Geology “St. Ivan Rilski”, Dept. of Geology and Exploration of Mineral Resources, 1700 Sofia; \\ E-mail: ina_bojinova@abv.bg
}

\begin{abstract}
The international practice often faces significant settlements of terrains and structures due to dewatering. This study presents of the dewatering impact during the construction of Metrostation 9-III from the Sofia Metropoliten on the surrounding terrains and buildings. The subsidences are quantified for specific values of the soil deformation modulus and varying values of the soil hydraulic conductivity.
\end{abstract}

Keywords: dewatering, subsidence, deformation modulus, hydraulic conductivity, Sofia Metropoliten.

\section{Въведение}

При оценката на влиянието на подземното строителство трябва да се има предвид влиянието на изкопните и отводнителни работи върху съседните сгради и съоръжения. В това отношение се вземат под внимание качеството на почвите, дълбочините на изкопите, разстоянието до и състоянието на съседните сгради, очакваното водопонижение, както в строителния изкоп, така и около него. От съществено значение е оценката на слягането на терена вследствие спадане на водното ниво и неговия ефект върху околното пространство.

\section{Обект на изследване}

Метростанция 9-III се намира при паметника на Патриарх Евтимий на кръстовището на ул. „Граф Игнатиев“ и булевардите „Левски“ и „Патриарх Евтимий“ (фиг. 1). Около станцията се намират сгради с възраст над 80 год. с изключение на сградата на БУЛГАРТАБАК, която е с носеща метална конструкция и е строена значително по-късно. Укрепителната конструкция на станцията се изпьлнява по т. нар. метод “Тор down", който състои в изпълнение на укрепителните стени и покривната плоча, след което се извършват подземни изкопи за метростанцията. Този метод не предполага неблагоприятни деформации на стените. Така, по отношение на влиянието на укрепителната система е прието, че няма да окаже въздействие на прилежащите сгради, терени и съоръжения. Съгласно инженерно-геоложкото проучване, нивото на подземните води е на дълбочина 5 m под повърхността на терена. Необходимото водопонижение за изпълнение на метростанцията е $16 \mathrm{~m}$. Ограждащите конструкции на строителната яма са шлицови стени, приети за водопльтни. Дьлбочините на забиване на стените под дъното на строителния изкоп са в два варианта $-8,65$ m и $6,10 \mathrm{~m}$ (Bozhinov, Popov, 2016).

\section{Резултати от инженерно-геоложките и хидрогеоложки проучвания}

Съгласно инженерно-геоложки проучвания строителните почви са представени от насипи, пясъци и глини. До дълбочини 4-4,5 m почвите са с кватернерена възраст. От гледна точка на слягания- 
та на сградите те не представляват особен интерес, тъй като котите на фундирането им са на тези дълбочини или по-ниски. По-надолу следват прослойки от пясъци и глини с плиоценска възраст. Тези почви са със здрави структури и високи деформационни модули. Дадени са стойности на тези модули, определени по лабораторен път и чрез SPT. Ударите по SPT за проникване на пенетрометьра на $30 \mathrm{~cm}$ са високи - над 50 , а дори понякога и до 100. Това показва здрави пластове, което се синхронизира с останалите данни за произход и якостни характеристики на почвите.

След подробен анализ на резултатите от изпитвания по метода SPT, както и по данни от пресиометрични изпитвания на подобни почви в Coфия, е определен среден деформационен модул на земната основа на сградите $\mathrm{E}=25 \mathrm{MPa}=25000 \mathrm{kPa}$ (Kostov, Bozhinova-Haapanen, 2015). С тази стойност са определени сляганията на терена вследствие водопонижението, свързано с изпълнението на Метростанция 9-III.

За оценка на ефекта от водопонижението следва да се определят и коефициентите на филтрация на литоложките разновидности. От данните на инженерно-геоложкото проучване се установява, че пластовете в дълбочина под котата на фундиране на сградите представляват повече или по-малко дебели прослойки от плиоценски пясъци и глини. Пясъците несъмнено са с високи коефициенти на филтрация, докато глините са в твърда консистенция с високи кохезии и се приемат за водонепропускливи. Общата мощност на глинестите пластове е 14-15 m. Пясъчните пластове, които се приемат за водопропускливи, имат сумарна дебелина 10 до $12 \mathrm{~m}$, т.е. може с основание да се приеме, че водоупорни и водопроницаеми пластове имат равно разпределение като прослойки в дълбочина. Очевидно, непроницаемите прослойки ще затрудняват вертикалната филтрация на подземните води при понижение на водните нива вследствие строителството.

От други публикувани източници (Smoltczyk, 1980) е установено, че водонепропускливите глини имат коефициенти на филтрация от порядъка на $10^{-8}$ до $10^{-9} \mathrm{~m} / \mathrm{s}\left(8,6.10^{-4} \mathrm{~m} / \mathrm{d}\right.$ до $\left.8,6 \cdot 10^{-7} \mathrm{~m} / \mathrm{d}\right)$. Песъчливите почви, които са водопропускливи, имат коефициенти на филтрация от порядъка на $10^{-4}$ до $10^{-5} \mathrm{~m} / \mathrm{s}(8,6$ до $0,86 \mathrm{~m} / \mathrm{d})$. Голямото разнообразие на литоложки разновидности с толкова различни коефициенти на филтрация не дава възможност за точно прогнозиране на поведението на подземните води по отношение на понижение на техните нива и водните количества.

Отсъства информация за влиянието на глинестите прослойки, които ще действат като водозащитни екрани и несъмнено ще препятстват вертикалната филтрация на подземните води. Направени са и изследвания за понижение на подземните води на различни нива, като е използван програмен продукт "Modflow".

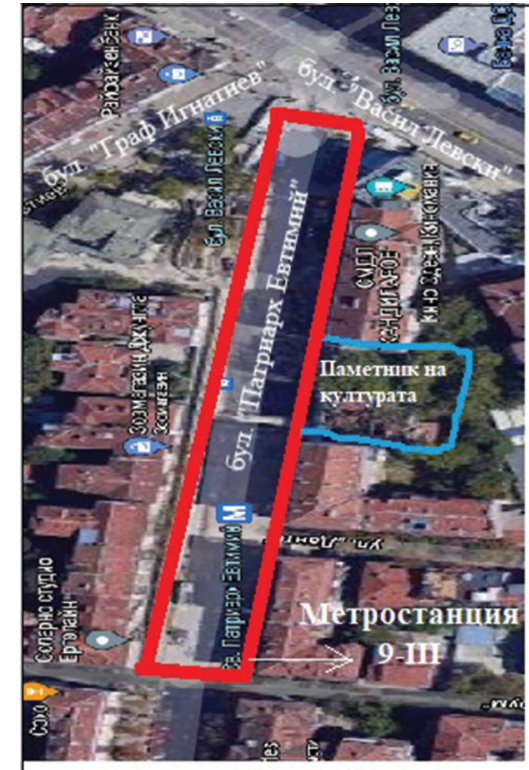

Местоположение на Метростанция 9-III

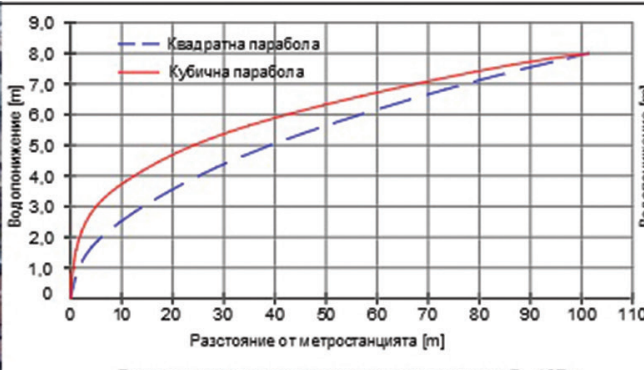

Депресионни криви при радиус на влияние $\mathrm{R}=107 \mathrm{M}$

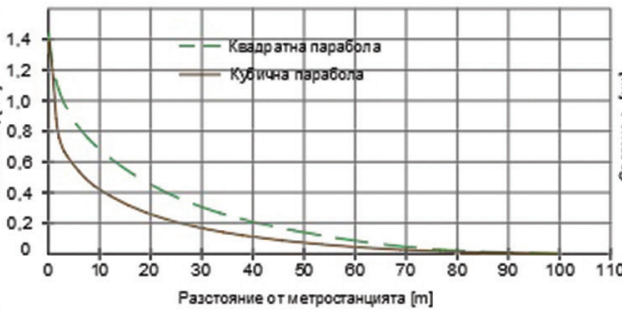

Криви на слягане при радиус на влияние $\mathrm{R}=107 \mathrm{M}$

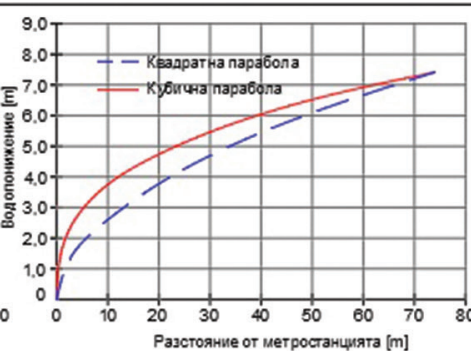

Депресионни криви при радиус на втияние $R=80 \mathrm{~m}$

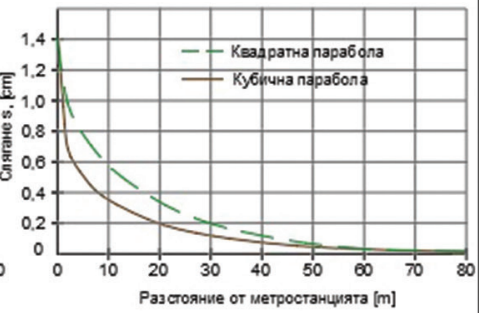

Криви на слягане при радиус на влияние $R=80 \mathrm{M}$

Фиг. 1. Местоположение на Метростанция 9-III, София. Графики на депресионни криви за различни стойности на коефициента на филтрация на почвите и съответното слягане на терена при различните радиуси на влияние. 


\section{Изследване на ефекта от водопонижението}

При оценка на ефекта от понижението на водното ниво върху слягането на околните терени може да се направи извод, че поради преграждане на водния поток от шлицовите стени може да се очаква подпор на водите откъм северозападната страна на метростанцията. Докато откъм страната на реката, където има сграда - паметник на културата (фиг. 1), се очаква по-значително спадане на нивото на подземните води - до $1 \frac{1}{2}$ от дълбочината на изчерпания воден стълб в изкопа, в случая до $8 \mathrm{~m}$. Това би могло да предизвика слягания на прилежащи сгради и терени.

Вследствие на елиминиране на водния подем се създават допълнителни напрежения в почвата. Слягането може да се определи като се раздели площта на диаграмата на тези напрежения на деформационния модул на почвата (Bozhinov, 2002). Пренебрегва се коефициентът на водоотдаване, което дава резултати в полза на сигурността.

От съществено значение е и очакваната неравномерност на слягането, която зависи от радиуса на влияние на депресионната фуния. Прилагайки известни аналитични зависимости (Smoltczyk, 1980), са направени изчисления за този радиус. Основна величина, меродавна за определянето му, е коефициентьт на филтрация на водовместващата среда. Предвид всички данни от инженерно-геоложките проучвания, за изчисленията може да се приеме усреднен коефициент на филтрация $\mathrm{k}=2 \cdot 10^{-5} \mathrm{~m} / \mathrm{s}$. При тези данни е получен радиус на влияние $\mathrm{R}=107 \mathrm{~m}$.

Експериментално е установено, че при водопонижение до $16 \mathrm{~m}$, зоната на влиянието му е приблизително $80 \mathrm{~m}$, т. е. $\mathrm{R}=80 \mathrm{~m}$. Като се използват аналитичните зависимости, може да се направят обратни изчисления, които дават друга стойност на среден коефициент на филтрация $\mathrm{k}=2,7.10^{-6} \mathrm{~m} / \mathrm{s}$. Тъй като има вариантни решения поради различни параметри на кривите на депресия, са направени съответните анализи и на фиг. 1 са показани графики на възможните депресионни линии за различните варианти: квадратни или кубични зависимости, както и слягането на терена при различни стойности на радиуса на влияние.

При всички случаи максималните очаквани деформации на терена са от порядъка на $1,5 \mathrm{~cm}$ и те засягат само силно ограничено пространство около изкопите за метростанцията. От получените графики се установява, че относителните слягания в рамките на една сграда са сравнително ниски и те също засягат само ограничени пространства около метростанцията. В отстояние на $10 \mathrm{~m}$ от шлицовите стени сляганията рязко намаляват - в рамките на 2 до $5 \mathrm{~mm}$, което е безопасно.

В резултат на направените проверки и изчисления се получава, че през време на строителството не трябва да се приемат каквито и да било предварителни мероприятия за осигуряване на околното пространство на тази метростанция. Тъй като някои от резултатите за запазване на околните сгради са „на ръба“, се изисква подробен и систематичен мониторинг за нивата на водите, измервания за слягане на съседните сгради и за устойчивост на дъното на изкопа, особено в последните фази на строителството.

\section{Заключение}

Точното определяне на слягането на околните терени дава възможност за предварителна оценка на влиянието на водопониженията върху съседните сгради и съоръжения при подземното строителство. Използването на получените резултати, предмет на настоящата разработка (които на практика се потвърдиха), даде основание да се избегнат скъпи технически решения за заздравяване на земната основа и фундаментите на сградите и съоръженията в близост до Метростанция 9-III, част от които са паметници на културата.

Благодарности: В представеното изследване са използвани изходни данни и документи за конструкциите и геоложките и хидрогеоложки условия на метрополитена, получени от проучвателни, проектантски и строителни фирми. Използвани са данни от инженерно-геоложки доклади на фирма „Геотехника АБС“ ООД, някои модели и експертизи относно изграждането на Софийския Метрополитен.

\section{Литература \\ References}

Bozhinov, B., S. Popov. 2016. Calculation of piles, diaphragm and sheet pile walls, loaded with horizontal forces and bending moments. - In: Bulgarian Association for Geotechnical and Tunnel Construction. Sofia, 273-277 (in Bulgarian).

Bozhinov, B. 2002. Experience in the underground construction in Sofia. - Ann. Univ. Archit., Gen. Civil, Geod., 40, 4, 151-160 (in Bulgarian with English abstract).

Kostov, V., A. Bozhinova-Haapanen. 2015. Settlement prediction for buildings founded on Pliocene clays from the territory of Sofia city. - In: Proc. 15th Intern. Multydisciplinary GeoConfer. SGEM, 2, 633-640.

Smoltczyk, U. 1980. Grundwasserstromung. - In: Grundbau Taschenbuch, 3. Auflage Teil 1. Berlin, Wilhelm Ernst \& Sohn, 229-264. 